\title{
Personal Management of Digital Information in University Students from a Gender Perspective
}

\author{
Patricia López Vicent ${ }^{1} \oplus$, José Luis Serrano ${ }^{2} \oplus$ and Isabel Gutiérrez Porlán ${ }^{2} \odot$ \\ ${ }^{1}$ Department of Theory and History of Education, University of Murcia, Spain \\ ${ }^{2}$ Department of Didactics and School Management, University of Murcia, Spain
}

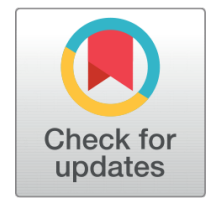

Received 2021-03-04

Revised 2021-03-11

Accepted 2021-04-30

Published 2022-01-15

\section{Corresponding Author}

Patricia López Vicent,

patlopez@um.es

Departamento de Teoría e Historia de la Educación, Facultad de Educación, Campus Universitario de Espinardo, 30100 Murcia, Spain

DOI https://doi.org/10.7821/

naer.2022.1.734

Pages: 114-129

Funding: Ministry of Economy and Competitiveness, Spain (Award:EDU2012-33256)

Distributed under CC BY-NC 4.0

Copyright: ( ) The Author(s)

\section{ABSTRACT}

The purpose of the present study is to delve into the process of personal management of digital information among Spanish university students in their final year and to analyze whether there are similarities or differences regarding students' gender. A non-experimental methodological design has been implemented of an exploratory type and based on a questionnaire as a single data collection instrument. The instrument was validated by means of experts' judgement, cognitive interview, and construct validity. A total of 2,054 students' surveys were collected, sourced from all areas of knowledge, in 75 public and private universities. These surveys made it possible to obtain information about the information search, selection, organization, processing, and creation processes. The results revealed that university students have a positive self-concept about their own competence for personal management of information. However, they fail to take advantage of all the possibilities that the digital world offers them. Women search the Internet for more diverse resources than men. They have better judgment when it comes to selecting and processing the information they need. Male students rely more often than female ones on digital mediums when organizing and creating information and choose to publish the information in less complex and more popular formats than their female counterparts. The conclusions of the present study match those of the majority of reviewed studies, namely regarding the organization of information, contextual and social factors which influence the management of information, such as third-party support, and also in relation to the increasing implementation of digital technologies in information management processes.

\section{Keywords INFORMATION COMPETENCY, ICT, DIGITAL DIVIDE, GENDER, UNIVERSITY, INFORMATION MANAGEMENT}

\section{INTRODUCTION}

Nowadays, we have a huge quantity of digital means at our disposal, practically in all areas of our lives, which results in a considerable amount of information being available. Undoubtedly, the competency to manage this information and transform it into knowledge

\section{OPEN ACCESS}


represents an important challenge in the digital world. In this sense, universities, as the main institutions responsible for the education of future professionals, need to address this demand and promote the development of students' information competency.

The study of this competency and the relationship people have with access to digital information is what is known in the field of research and specialized literature (Alon \& Nachmias, 2020; Feng \& Agosto, 2019; Ferrán-Ferrer \& Pérez-Montoro, 2009; Hajibayova, 2019; J. Jones \& Teevan, 2007) as Personal Information Management. We are talking about a complex concept which can be interpreted from different perspectives. From a disciplinary perspective, we find an area of study where the theoretical foundations of information sciences are combined with research on computer mediated communication (Feng \& Agosto, 2019). However, from the perspective that considers the active role of Internet users (J. Jones \& Teevan, 2007), Personal Information Management is understood as the realization of different tasks which people develop so as to accomplish different professional, personal, and social responsibilities which include access, creation, organization, storage, retrieval, utilization and distribution of information.

Along the same lines, and at an international level, the American Library Association (2000) alludes to the acknowledgement of informational necessities, but also to the ability to search, assess, process, and produce information, as well as to ethical and social components of the use of information. More recently, the European Framework for the Digital Competence of citizens (DIGCOMP), published by the European Union (Ferrari, 2013) includes as key elements in information management in digital environments, Internet navigation, searching, filtering, data evaluation and management, information, and digital contents.

The main objective of the research detailed in the present article is to analyze what kind of Personal Information Management processes are implemented by students of the final year in Spanish universities. Therefore, processes of searching, selection, organization, processing, and creation of digital information are studied. Moreover, this analysis is carried out taking into consideration the similarities and differences which can be detected depending on the students' gender since, as will be detailed subsequently, there are few studies which analyze this aspect, although the ones which have been already developed reveal highly relevant results for the present study (Ali \& Warraich, 2021; Alon \& Nachmias, 2020).

The research related to this topic can be of a complex nature. The concept of Personal Information Management is composed of different types of processes which can be perceived interchangeably, especially by the users themselves when they are asked about those processes. Different authors have contemplated the challenges that Personal Information Management comes across in technological environments, highlighting the great amount of information that we have access to, the prediction of the informational value, the fragmentation of information, technological obsolescence, and the use of different devices by the same user (Ali \& Warraich, 2021; Bergman, 2013; Kearns, Frey, Tomer, \& Alman, 2014; Marshall, 2007; Sinn, Kim, \& Syn, 2017; Zhong, 2013).

The interest in the knowledge and improvement of Personal Information Management skills in students is due to the fact that the higher competence students give it greater consideration when managing their personal information, hence less stress is experienced, more 
time is saved, and there is a greater feeling of efficiency and efficacy generated and, what is more, the feeling of being overwhelmed by information is mitigated (S. Jones \& Thomas, 1997). It is necessary to get past fragmented research (Ferrán-Ferrer \& Pérez-Montoro, 2009) and attempt to offer a global and comprehensive knowledge of Personal Information Management, something which turns out to be challenging, as it is difficult to obtain a unified vision of the different approaches to it, as these are implemented from different sub areas (Indratmo \& Vassileva, 2008). For this reason, this research is conceived with the purpose of analyzing all dimensions of Personal Information Management.

The studies on how people manage their personal information carried out a number of years ago were limited to the business and finance environment (Bergman, Beyth-Marom, \& Nachmias, 2003; Chaudhry, Rehman, \& Al-Sughair, 2015; Erickson, 2006; S. Jones \& Thomas, 1997). Over the years, new lines of research have emerged from the field of Educational Sciences, which are centered on teachers and the academic environment (Diekema \& Olsen, 2014; Kearns et al., 2014; Sedghi, Abdolahi, Azimi, Tahamtan, \& Abdollahi, 2015). However, some works which have explored the actual usage of each of the actions carried out by university students within the scope of Personal Information Management (Alon \& Nachmias, 2020; Arias \& Simón, 2008; Comas, Sureda, Pastor, \& Morey, 2011; Sureda, Comas, \& Urbina, 2007). Among these actions, we can highlight the work of Syn, Sinn, and Kim (2020), in which the authors found that students' perceptions and contexts heavily influence their information management processes and the type of resources they use. In line with the work herein presented, Stewart, Basic, and Erdelez (2012), Ameen (2016), Faize, Waqar, and Mubeen (2018) and Harisanty (2018) described what the students' Personal Information Management competency.

In the research explained in the present article, we aim to find out whether gender has an influence on Personal Information Management or not. There are not many studies which have examined this relationship. In this sense, the studies by Alon and Nachmias (2020) and Warraich, Ali, and Yasmeen (2018) are worth highlighting; in those, the usefulness of an efficient Personal Information Management system and a greater gap of knowledge in women compared to men is evidenced.

In general, research on university students' Personal Information Management highlights the difficulties and limitations it entails when developing those processes linked to PIM. The need to improve training in this regard is clear (Ameen, 2016; Otopah \& Dadzie, 2013). A holistic approach to this competence which goes beyond the search of information, and which encompasses the rest of actions related to Personal Information Management, such as storage and further retrieval of information should be promoted (Stewart et al., 2012).

The improvement of training in university students' Personal Information Management should be supported with greater evidence than what currently exists. This is the main contribution of the present study, as it analyzes the process of digital information management of university students in their final year in Spanish universities and whether there are similarities or differences regarding gender. With this purpose, we intend to answer the following research enquiries: 
1. Which resources and strategies do university students use when wanting to search for information?

2. Which are the criteria and strategies used to select the information?

3. Which are the procedures and technologies used by university students to organize the information once this has been selected?

4. Which strategies and technologies are used to process information?

5. When they create information, which strategies and instruments are used? Do they need extra help?

Finding answers to these questions allows us to tackle the goal of this research, which aims to understand how Spanish university students of any area of knowledge rely -or not- on technology to search, select, organize, process, and create digital information. Throughout this process we have deemed it interesting to explore the influence of gender, mainly due to the lack of studies on this issue, to the importance given to gender when talking about the digital gap and the growing number of policies and actions at a national and international level oriented towards the real integration of women into the digital world. This angle would allow for the design of didactic strategies and educational initiatives which foster the process of digital PIM through a gender perspective whenever it is necessary. Similarly, this could contribute to improving the efficiency in the use of technology in a connected world, which is characterized by the wide range of information which, on many occasions, has low or questionable quality.

\section{METHODS}

\subsection{Participants}

This study's population is large and geographically dispersed. It consists of a total of 298,000 university students in their final year registered in the 84 Spanish public and private universities. Due to the characteristics of this population and the difficulties that accessing the whole population implies, we opted for distributing the data collection instrument among the participants, chosen from an international sample.

A total of 2,054 valid surveys were collected from 75 different universities. This sample facilitates obtaining consistent evidence about the subject of study, being representative, while not in a statistical sense and with no aim of generalizing to the rest of the study population. In Figure 1 we show the distribution of the population and the sample in relation to the different areas of knowledge. We find it remarkable that women represent $69.7 \%$ of the sample, compared to men, who are $30.3 \%$ of said sample, and the area of knowledge with more presence being Social and Legal Sciences (43\%).

\subsection{Instrument}

In the present study we followed a non-experimental design of an exploratory type and relied on a questionnaire as the only data collection instrument. This questionnaire was designed and validated within the framework of the CAPPLE project with the purpose 


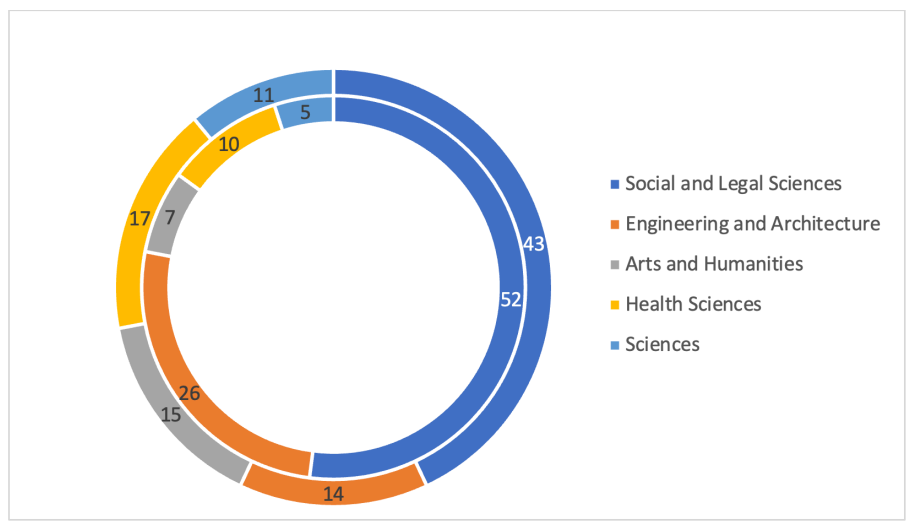

Figure 1 CAPPLE Project population and sample (\%)

of collecting information about the perception that university students -from any field of knowledge- have about the way they learn.

As described in Prendes, Castañeda, Ovelar, and Carrera (2014) and Prendes et al. (2016), for the design of this questionnaire, we departed from the review of specialized literature on personal learning environments (Castañeda \& Adell, 2013), learning strategies and self-regulated learning (Anderson, 2002; Boekaerts, 1997; Martín, García, Torbay, \& Rodríguez, 2007; Midgley et al., 2000; Pintrich, Smith, García, \& Mckeachie, 1991), learning strategies and ICT competencies, and communication (Prendes, 2010; Prendes \& Gutiérrez, 2013).

On the basis of the key references cited in the previous paragraph, the research group of the CAPPLE project came up with a list of recommendations where the kind of data which needed to be collected and the type of item worth contemplating, in view of the core subjects presented above, were stated. This list was subjected to several proofreading rounds in small work teams consisting of the project's research group itself (Prendes et al., 2014).

In order to guarantee the reliability, validity and functionality of the data collection procedure, a three-step questionnaire validation process was carried out. First, a construct validation was implemented through the expert judgement technique by means of the individual addition method. Eight professionals (one per each of the universities involved) took part in the three consecutive proofreading rounds carried out. The duty of the experts was to assess the relevance and congruence of the questions and items with the theoretical content and to evaluate the wording and the bias in the items.

Secondly, and based on a new version of the instrument after the experts' judgment, the concurrent survey validation technique through cognitive interview was implemented to enhance the validity of $10 \mathrm{key}$ items in the instrument, taking into account the information provided by 24 students at the universities of the Basque Country, Oviedo, Murcia and Las Palmas de Gran Canaria. After the pertinent data analysis, a series of recommendations and proposals for improvements regarding methodological, content, spelling and stylistic aspects were elaborated, and these recommendations led to a new version of the question- 
naire, based on which the pilot test, the third validation procedure, was designed. In this case, 224 students (a sample of 406 invited female and male students) belonging to the different universities involved in the project, took part in the test. Finally, it should be added that psychometric tests were used to determine the reliability of the scale, adding up to a 0.944 Cronbach Alpha coefficient.

All the validation process is thoroughly described in Prendes et al. (2016), as well as the different versions of the questionnaire. The instrument consists of 48 questions, 35 of which have a 5-level scale (always/almost always; often; sometimes; seldom; hardly ever/never), plus the option "non applicable".

Emailing was the most common instrument for the distribution of the questionnaire, run via network management by means of the Survey Monkey tool.

To meet the objectives of the study detailed in the present article, the items and questions which can be found in the Appendix A.

\section{RESULTS}

Bearing in mind the nature of the study variables analyzed in the present work (all of them categorical) a descriptive analysis of each one of them has been performed. Additionally, simultaneous associations between two variables to determine potential significant relationships have been carried out. For this purpose, contingency tables are utilized, and the Pearson's chi-squared test for testing statistical independence, and the contingency coefficient $\mathrm{C}$ association measurement.

The maximum contingency coefficient is 0.86 in all the cases. Only the statistically significant variables with a moderately high (between $60 \%$ and $75 \%$ ) or high (higher than $75 \%$ ) degree of relationship have been selected after contrasting both coefficients. No significant associations with a degree of association higher than $81.3 \%$ have been identified.

The data treatment and analysis has been carried out with the statistical program IBM (version 24 for Windows).

The results are displayed according to the research questions, by means of which we intend to analyze what the Personal Information Management process is like in university students, as well as to identify the similarities and differences regarding gender.

\subsection{What resources and strategies do university students use when looking for information?}

Firstly, the tools students rely on when wanting to obtain information are analyzed. We observe that $83.6 \%$ of students always or very frequently use exploratory searches on web browsers.

Regarding the use of resources to obtain different types of information, students almost always or very frequently only use a general search engine, like Google or Yahoo when looking for information (60\%), libraries and networking databases (16.7\%), various general search engines (11.5\%), specialized thematic search engines $(7.7 \%)$, specific or thematic search engines (3.3\%), social networks $(0.2 \%)$ and discussion forums $(0.2 \%)$. 
Secondly, the resources oriented towards the search of information for research and professional development are analyzed. In relation to searching for information by means of exploratory searches in manuals, textbooks, and encyclopedias, it is worth highlighting that women are above men in this regard (59.4\% compared to 40.6\%) There are not huge differences between students regarding searches by authors or in specialized journals, since respectively $36 \%$ and $26.6 \%$ of students always or often use this type of search. However, male students outdo female students regarding search of information in specialized websites (59.7\% of men compared to $40.3 \%$ of women).

Thirdly, the results obtained in relation to the resources used for the dissemination of information are shown. There are some resources which are used very frequently by students in general when they want to search for information, while others are seldom or hardly ever used. In this way, students as a whole always or often use blogs or websites (72\%), encyclopedias online (67.4\%), video tutorials, network tutorials, or slides (57.7\%), and friends who are present $(46.5 \%)$. However, female students surpass male students regarding the use of online media ( $69.1 \%$ of women compared to $57.3 \%$ of men).

On the other hand, the resources that students seldom, or never use when searching for information are specific mobile phone applications (52.7\%), social networking sites (46.4\%) and discussion forums (41.3\%).

However, there are remarkable differences between female and male students in relation to searching for information through friends they make contact with by means of email or private text messages on platforms such as Facebook, DM on Twitter, WhatsApp, etc., since while $39.2 \%$ of women always or often use them, $37.08 \%$ of men seldom or never use them.

\subsection{Which are the criteria and strategies they use to select information?}

Thanks to the following results, we can identify some relevant aspects regarding the selection of information that students have previously searched for such as: criteria they use to select said information, the format in which they prefer that information to be presented, how the information is questioned depending on the medium, resource, or tool it comes from, and the credibility given to the information they find.

Criteria to select information. From the information students come across, they stress that they always or often select the one which is most frequently updated (82.6\%), the information which is based on a clear blueprint (76\%), the one which one is made to revise $(65.8 \%)$ or the information that is recommended to be checked (53.3\%). It is worth noting that the students affirm that they only select the information presented in audiovisual means occasionally (37.2\%).

Preferences for the format of the information selected. Students on the whole tend to always, or often work with iconic information (75.6\%), video $(65.9 \%)$ or multimedia (57.8\%), whereas they seldom or never work with the audio form (39.3\%). It is worth highlighting that most of the students answer "non-applicable" when they are asked about the hypermedia format (29.4\%). 
Questioning of the information prior to the selection. Students always or very often question the information they obtain from social media $(72.2 \%)$, discussion forums (61.6\%), online media (69.8\% of male students and $59.2 \%$ of female students), blogs and websites (61.2\%), traditional means of communication $(67.5 \%$ of men and $53.2 \%$ of women), news they receive via email (61\% of men and $49.6 \%$ of women) and family members or friends (53.9\% of male students and $42.2 \%$ of female students).

It is worth noting that they seldom or never question the information provided by experts and other professionals in the field (65.9\%) nor that provided by their teachers (48.5\%).

Credibility of the information selected. Students always or very often give credibility to the information recommended by an expert (89.8\%) and the one which appears in different resources, such as network articles, books, or videos (79.6\%). Students seldom or never give credibility to information recommended in social media (50\%), or that which appears in the first positions in Google search results (37.5\%).

\subsection{What are the procedures and technologies used by students to organize their information once it has been selected?}

In relation to this aspect, we intended to identify the strategies that students use to organize their information and the preferred storage spaces to store saved information.

Strategies to organize information: the preferred strategy to organize information is by distributing it in (hierarchical) folders, as $94.6 \%$ always or very often use this strategy. However, it is important to remark that students on the whole seldom or never use social networking tools to manage information (48.3\%), nor do they manage information according to a timeline (44.6\%). We should highlight that the majority of students choose the option "non-applicable" regarding the use of social bookmarking sites (52.8\%) and wikis (49.2\%).

Finally, it needs to be noted that we find differences between male and female students in relation to the use of blogs when doing these kinds of activities, since the majority of women choose the option "non-applicable" (47.8\%) for this item, compared to $44.6 \%$ of men, who state they seldom or never use blogs to organize information.

Preferred storage spaces. Almost all of the students always or very often prefer using both physical and virtual, network spaces (92.5\%). However, students on the whole state that they seldom or never store the information exclusively online (51.7\%), specifically, in spaces such as the cloud (50.7\%).

\subsection{Which strategies and technologies do they use to process information?}

Students on the whole always or very often save the information carefully $(87.3 \%)$, use some sort of outline or conceptual map to link the information (40.9\%), or summarize it (43.1\%).

Students in general always or very often link the new information they find with what they already know (89.3\%), analyze it (97\%), interpret it (85.8\%), contrast it with what they already know (84.3\%), find the information raises doubts or questions (79.1\%), and contrast it with other sources (66.5\%). 
Regarding the process followed when encountering an interesting document, we observe that students always or very often read the printed document, underline it, takes notes on the same document, and transcribe those notes onto a paper document (60.4\%) and always or very often download the document on their computer and take notes with a specific tool while they are reading the document on the screen (68\%). However, some remarkable differences are found between both sexes in relation to the use of metadata included in their own resources, as $45 \%$ of male students state they seldom or never carry out this activity, whereas $40.4 \%$ of female students choose the option "non-applicable".

Finally, reading online documents and taking notes on a specific online tool such as Diigo (35.9\%) or including specific bibliographic tools in these documents, such as Mendeley or RefWorks, and taking notes based on said documents (41\%) are actions for which students, on the whole, choose the option "non-applicable".

In relation to the way forward when finding an interesting video or audio, students always or very often listen or watch it online and take notes about it on a piece of paper $(59.3 \%)$ and they always or very often watch the video or listen to the audio online and take notes on a text document on the computer, although women do this more often than men (46.6\% of female students and $36.6 \%$ of male students). However, more than half of the students state that they seldom or never listen to the audio or watch the video online and take notes using a specific software for word processing (52.7\%).

\subsection{When they create information, what strategies and tools do they use? Do they look for help?}

The strategy implemented in the creation of information. Students in general always or very often choose information they consider to be relevant and, based on that, they create something new (73.4\%), while they seldom or never create something completely new, from scratch, without looking for references (55.5\%).

The ethical component in the creation of information. When students use information from a third-party source, female students show greater respect for copyrights ( $83.3 \%$ of female students always or very often do so, compared to $67.1 \%$ of male students), cite the source more often $(86.5 \%$ of female students always or very often do so, compared to $76 \%$ of male students), and demonstrate greater respect for the type of license which protects said source ( $71.8 \%$ of females always or very often do so, compared to $57.4 \%$ of males).

To create information which they later wish to publish online, women (50.5\%) always or very often rely on draft documents, more so than men (38\%), while no remarkable differences are observed when they rely on classmates with whom they discuss what they are creating (34.1\%), or when they rely on digital drafts (41.6\%).

However, they seldom or never rely on fellow students who proofread their work before publishing it (35.8\%).

In spite of the above, students on the whole never reject external help, since they seldom or never directly edit and publish the information without getting any type of help, although women resort more often to the help of others than men (51.4\% of female students versus $39.3 \%$ of male students). 
It is worth stressing noticeable differences between men and women regarding the people they ask for help: while female students state that they always or very often rely on teachers or experts who proofread their work (33.6\%), male students say they seldom or never do so (35.6\%).

When they wish to elaborate new information to publish it online, students in general state that they seldom or never know how to do it (41\%). In this way, the majority of students always or often publish the information on the social networking sites they habitually use, although women do so more often than men (38.5\% of female students and $29.6 \%$ of male students). Besides, men state that they seldom or never use one or another type of tool depending on the type of information they deal with (30.4\%), while $30.1 \%$ of women choose "non-applicable" in this option. Something similar occurs in relation to the use of specific tools such as blogs to publish information online, where most of the students select the option "non-applicable", too (36.7\%).

Regarding the format of the digital content the students create and share online, the majority state that they seldom or never tend to publish audio content (49.3\%), multimedia $(42.7 \%)$ or video format $(38.3 \%)$. However, it is worth noting that male students always or very often prefer to publish content in text form (34\%), whereas female students always or very often prefer to publish iconic information (44.4\%). Finally, the majority of students select the option "non-applicable" when they are asked about publishing hypermedia content, probably because they do not know what it is (49.7\%).

With regard to the significant associations between categorical variables in the questionnaire, we firstly find that those students who give credibility to the information they receive when this information is endorsed by friends and relatives have a moderately high degree of association with those students who give credibility to the information recommended on social media (Table 1).

Table 1 Chi-square value and contingency coefficient $\mathrm{C}$ about the credibility given to the information that students receive.

The information is endorsed by friends and relatives

\begin{tabular}{lll}
\hline & $\mathbf{X}^{2}$ & $\mathbf{C}$ \\
The information recommended on social media & $\mathrm{X}^{2}(9,2054)=805.729^{a * * *}$ & .531 \\
\hline Note: ${ }^{\star * \star} \mathrm{p}<.001 ; \mathrm{C}=$ Contingency Coefficient & &
\end{tabular}

Another moderately high association is the one we find between the students who question the information they receive from traditional media with the ones who question the information when they receive it from online media (Table 2). The same type of relationship exists between those students who question the information they receive from social media and those who receive it from discussion forums (Table 3 ).

The only high association we find is the one which connects those students who describe themselves as responsible and respectful with copyrights and those who respect the type of license which protects the contents when they are using information from a third party (Table 4). 
Table 2 Chi-square value and contingency coefficient $\mathrm{C}$ between the information they question when this is received from different sources (traditional and online media)

The information they receive from traditional media

\begin{tabular}{lll}
\hline & $X^{2}$ & $C$ \\
The information they & $X^{2}(9,2054)=1460.092^{a * * *}$ & .645 \\
receive from online media & & \\
\hline
\end{tabular}

Note: ${ }^{* *} \mathrm{p}<.001 ; \mathrm{C}=$ Contingency Coefficient

Table 3 Chi-square value and contingency coefficient $\mathrm{C}$ between the information they question when this is received from different sources (social media and discussion forums).

The information they receive from social media

\begin{tabular}{lll}
\hline & $\mathrm{X}^{2}$ & $\mathrm{C}$ \\
$\begin{array}{l}\text { The information they receive } \\
\text { from discussion forums }\end{array}$ & $\mathrm{X}^{2}(9,2054)=1107.257^{a \star * *}$ & .592 \\
\hline
\end{tabular}

Note: ${ }^{\star * \star} \mathrm{p}<.001 ; \mathrm{C}=$ Contingency Coefficient

Table 4 Chi-square value and contingency coefficient $\mathrm{C}$ about the use of third-party information.

The students are responsible and respectful with copyrights

\begin{tabular}{lll}
\hline & $\mathbf{X}^{2}$ & $\mathrm{C}$ \\
$\begin{array}{l}\text { The students respect the type } \\
\text { of license }\end{array}$ & $\mathrm{X}^{2}(9,2054)=2069.426^{a * * *}$ & .708 \\
\hline
\end{tabular}

Note: $\left.{ }^{\star} \mathrm{p}<.05 ;{ }^{\star *} \mathrm{p}<.01 ; \mathrm{N}=48\right)$

We finish this analysis with a moderately high relationship between students who publish information on social networking sites they use habitually when they want to create new content online and those students who use tools such as blogs to do so (Table 5).

Table 5 Chi-square value and contingency coefficient $\mathrm{C}$ between tools used to create and publish new information online

The students publish information on social networking sites they use habitually when they want to create new content online

\begin{tabular}{lll}
\hline & $\mathbf{X}^{2}$ & $\mathrm{C}$ \\
$\begin{array}{l}\text { The students use tools such } \\
\text { as blogs to create new content }\end{array}$ & $\mathrm{X}^{2}(9,2054)=800.985^{a * * *}$ & .530 \\
online & & \\
\hline
\end{tabular}

Note: ${ }^{* *} \mathrm{p}<.001 ; \mathrm{C}=$ Contingency Coefficient

\section{DISCUSSION AND CONCLUSIONS}

In the study analyzed in the present article, we intended to identify the process of Personal Management of Digital Information carried out by university students and whether there are differences in its development depending on the gender. There is not a great deal of 
research centered on this specific issue. This was precisely one of the main reasons which motivated the search for possible differences regarding gender in the framework of this research. Warraich et al. (2018) found that the practices developed when managing information were equally useful for men and for women. However, women had to deal with bigger challenges, since the problems and difficulties deriving from this practice turned out to be greater for them. Along the same lines, Alon and Nachmias (2020) found a greater knowledge gap in women compared to men.

The main conclusions derived from the results obtained in this study can be seen in Figure 2, where those aspects where men and women stand out in each of the phases of the Personal Management of Digital Information process, in university students. In that figure, it can be seen that women conduct searches through a greater variety of resources compared to men. However, it is men who question more the information when they select it, even though female students process information more deeply than male students when the information they find is published in audio or video format. Finally, women create information in a more complex manner than men, as they respect copyrights and licenses and cite the source, rely on draft paper and third parties before publishing their work and when they do so, they use more sophisticated tools and formats than men.

In this information-sharing process where we have found out that women are more competent than men, Stewart et al. (2012), Ameen (2016) and Harisanty (2018) discovered that the subjects who took part in their research felt comfortable sharing information with their male and female peers, an aspect which confirms the results of the research conducted by Harisanty (2018). In the latter study, we find the explanation for this difference regarding gender, as the social and affective nature of the management of information was identified, stressing the importance of trust in the social group when it comes to finding reliable sources of information. The credibility of information is one of the greatest difficulties highlighted in the cited study. Moreover, this research emphasizes the importance of the contextual and social factors occurring during the Personal Information Management process which could affect differently depending on the gender.

If we focus on the Personal Information Management process performed by the students surveyed in the present research, we find that even though they still carry out management strategies of a rather analogic type, there is a growing inclusion of digital resources in the Personal Information Management processes developed. In this sense, we can highlight the work by Alon and Nachmias (2020), where it was found that university students wished to make a greater use of digital devices to manage their information and, what is more, they were interested in enhancing their abilities in this regard. On the other hand, the results of our study can be explained based on the details exposed by Arias and Simón (2008), Comas et al. (2011) and Sureda et al. (2007), when they state that university students, in spite of the difficulties they have to manage their personal information, possess a rather positive self-concept in relation to their abilities and capacities to search for and locate information, echoing our study in that this is the most remarkable aspect in the surveyed students.

Taking a closer look into the Personal Information Management process, the conclusions presented in this study regarding the organization and processing of information match the 


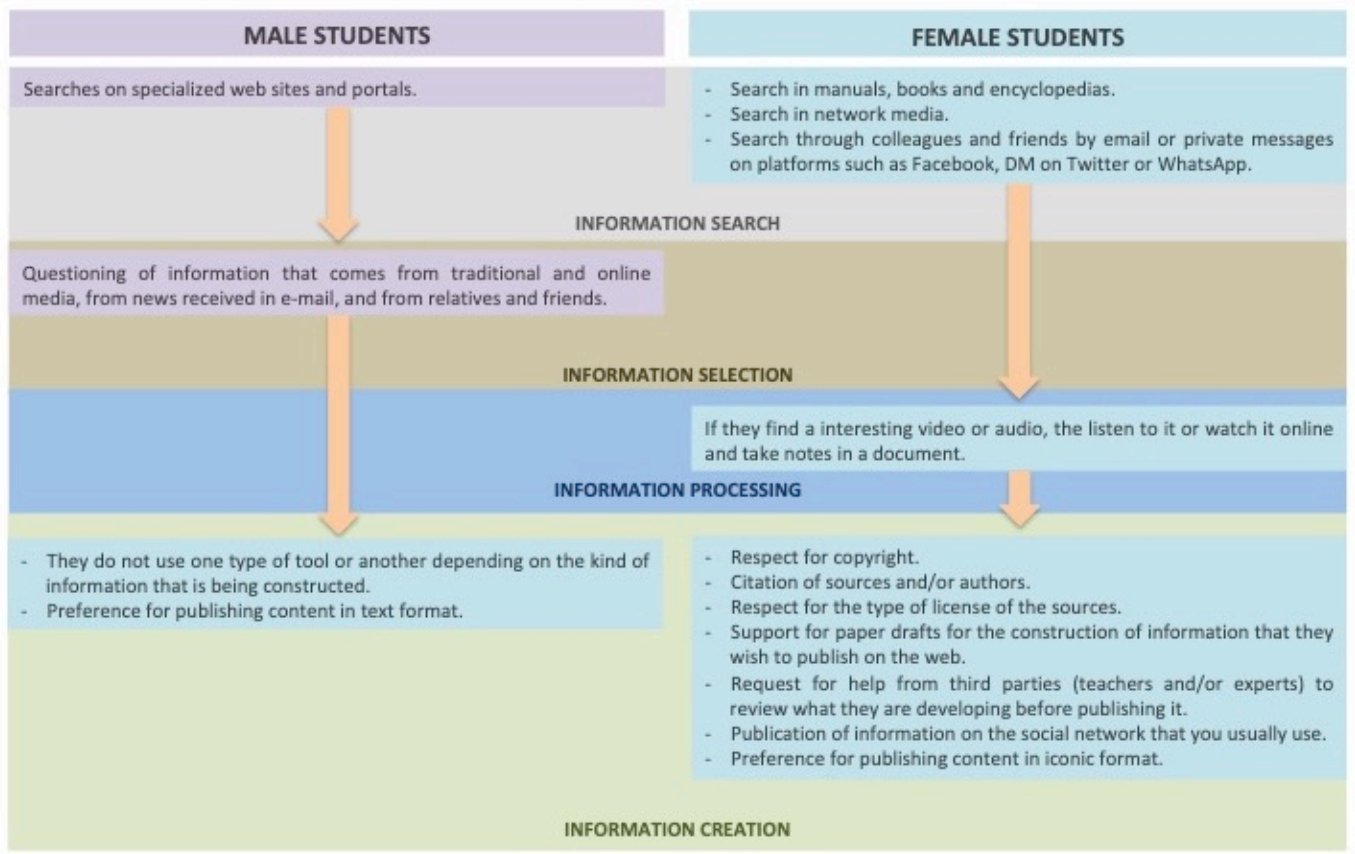

Figure 2 Principal research conclusions

results of studies such as the ones by Stewart et al. (2012), Ameen (2016), Faize et al. (2018) and Harisanty (2018), all of which found that information is stored -principally- on the local computer hardware, making several backup copies, divided by topics. In order to retrieve and search for information, the people surveyed opted for going directly to the file, instead of using a search assistant, showing a preference for retrieval processes reliant on human methods (Whittaker, 2011).

In this sense, the results evidence that some implications such as setting training programs aimed at the improvement of Personal Information Management for those students who lack sufficient competence can be useful. Additionally, it implies that universities provide students with resources, and especially, teaching methodologies which promote the practice of Personal Information Management processes which will be necessary in the development of their future professional activity.

Training programs can be integrated in a transversal fashion in university subjects, in a more specific way in some of them, and even as complementary subjects through training courses. In any case, in future studies, it would be necessary to evaluate the impact of these training initiatives and determine which type of training is the most effective and why.

The limitations of the present study are related to its methodological aspects. On the one hand, the breadth of the dimensions of the questionnaire and the information collection technique could lead to a sample mortality rate. On the other hand, the sampling technique used does not allow for the results to be generalizable.

Another limitation of the study had to do with not having been able to implement other instruments of a qualitative type which make possible the triangulation of the collected data. 
Nevertheless, the information obtained in the present research, and the one which could be offered in future works could lead to a deeper understanding of the issue, in relation to new educational and gender policies which are aimed at guaranteeing equal opportunities for all and whose purpose is the improvement of the personal management of digital information of future professionals.

\section{ACKNOWLEDGEMENTS}

This article originates from the CAPPLE project: Competences for Permanent Learning, based on the use of Personal Learning Environments, Analysis of future professionals and proposals for improvements (Reference EDU 2012-33256), which was funded by the Spanish Ministry of Economics and Competitiveness.

Funded by: Ministry of Economy and Competitiveness, Spain

Funder Identifier: http://dx.doi.org/10.13039/501100003329

Award: EDU2012-33256

\section{ADDITIONAL INFORMATION AND DECLARATIONS}

Data set: López Vicent, P., Serrano Sánchez, J. L., \& Gutiérrez Porlán, I. (2021). Personal Managment of Digital Information in University Students from a Gender Perspective [Data set]. Zenodo. https://doi.org/10.5281/zenodo.5724049

\section{REFERENCES}

Ali, I., \& Warraich, N. F. (2021). Modeling the process of personal digital archiving through ubiquitous and desktop devices: A systematic review. Journal of Librarianship and Information Science. https://doi.org/10.1177/0961000621996410

Alon, L., \& Nachmias, R. (2020). Gaps between actual and ideal personal infor-mation management behavior. Computers in Human Behavior, 107, 106292. https://doi.org/10.1016/j.chb.2020 .106292

Ameen, K. (2016). Personal Information Management Practices and Behaviors of Social Sciences' Students. Pakistan Journal of Information Management \& Libraries, 18(1), 12-24.

American Library Association. (2000). Information Literacy Competency Standards for Higher Education. Retrieved from http://www.ala.org/acrl/ilcomstan.html

Anderson, P. (2002). Assessment and development of Executive Function (EF) During Chilhood. Child Neuropsychology, 8(2), 71-82. https://doi.org/10.1076/chin.8.2.71.8724

Arias, A., \& Simón, J. (2008). Estudio de los hábitos de uso de los estudiantes en la biblioteca de la Universidad Complutense de Madrid. Revista española de Documentación Científica, 31(3), 413-431. https://doi.org/10.3989/redc.2008.v31.i3.436

Bergman, O. (2013). Variables for personal information management research. Aslib Proceedings, 65(5), 64-483. https://doi.org/10.1108/AP-04-2013-0032

Bergman, O., Beyth-Marom, R., \& Nachmias, R. (2003). The user-subjective approach to personal information management systems. Journal of the American Society for Information Science and Technology, 54(9), 872-878. https://doi.org/10.1002/asi.20738 
Boekaerts, M. (1997). Self-regulated learning: a new concept embraced by re-searchers, policy makers, educators, teachers, and students. Learning and instruction, 7(2), 15-16. https:// doi.org/10.1016/S0959-4752(96)00015-1

Castañeda, L., \& Adell, J. (2013). Entornos Personales de Aprendizaje: claves para el ecosistema educativo en la red. Marfil.

Chaudhry, A. S., Rehman, S., \& Al-Sughair, L. (2015). Personal information management practices in the Kuwaiti corporate sector. Malaysian Journal of Library and Information Science, 20(3), 27-42. https://mjlis.um.edu.my/article/view/1773

Comas, R., Sureda, J., Pastor, M., \& Morey, M. (2011). La búsqueda de informa-ción con fines académicos entre el alumnado universitario. Revista Española de Documentación Científica, 34(1), 44-64. https://doi.org/10.3989/redc.2011.1.769

Diekema, A. R., \& Olsen, M. W. (2014). Teacher Personal information management (PIM) practices: Finding, keeping, and Re-Finding information. Journal of the Association for Information Science and Technology, 65(11), 2261-2277. https://doi.org/10.1002/asi.23117

Erickson, T. (2006). From PIM to GIM: Personal information management in group contexts. Communications of the ACM, 49(1), 74-75. https://doi.org/10.1145/1107458.1107495

Faize, F., Waqar, H., \& Mubeen, A. (2018). Exploring Students' Competency in Personal Information Management: Problems and Prospects. Pakistan Journal of Information Management \& Libraries, 20,1-18. Retrieved from https://is.gd/JwUQg5

Feng, Y., \& Agosto, D. E. (2019). Revisiting personal information management through information practices with activity tracking technology. Journal of the Association for Information Science and Technology, 70(12), 1352-1367. https://doi.org/10.1002/asi.24253

Ferrán-Ferrer, N., \& Pérez-Montoro, M. (2009). Gestión de la información personal en usuarios avanzados en TIC. El profesional de la información, 18(4), 365-373. https://doi.org/10.3145/ epi.2009.jul.02

Ferrari, A. (2013). DIGCOMP: A framework for developing and understanding digital competence in Europe. Luxembourg Publication Office. https://doi.org/10.2788/52966

Hajibayova, L. (2019). Exploring individuals' patterns of personal information management practices: factors influencing the representation, organization and credibility assessment of information. Information Research, 24(3). Retrieved from http://nformationR.net/ir/24-3/ paper835.html

Harisanty, D. (2018). Personal information management of urban youth. Library Philosophy and Practice, 1944.

Indratmo, I., \& Vassileva, J. (2008). A review of organizational structures of personal information management. Journal of Digital Information, 9(1), 1-12.

Jones, J., \& Teevan, J. (2007). Personal Information Management. University of Washington Press.

Jones, S., \& Thomas, P. J. (1997). Empirical assessment of individuals' 'personal information management systems. Behaviour and Information Technology, 16(3), 158-160. https://doi.org/ $10.1080 / 014492997119888$

Kearns, L. R., Frey, B. A., Tomer, C., \& Alman, S. (2014). A study of personal information management strategies for online faculty. Journal of Asynchro-nous Learning Network, 18(1). http://doi.org/10.24059/olj.v18i1.296

Marshall, C. (2007). How people manage information over a lifetime. Personal Information Management (pp. 57-75). University of Washington Press.

Martín, E., García, L. A., Torbay, A., \& Rodríguez, T. (2007). Estructura factorial y fiabilidad de un cuestionario de estrategias de aprendizaje en universitarios: CEA-U. Anales de psicología, 23(1), 1-6. Retrieved from https://www.redalyc.org/pdf/167/16723101.pdf

Midgley, C., Maehr, M., Hruda, L., Anderman, E., Anderman, L., Freeman, K., \& Urdan, T. (2000). 
Manual for the Paterrns off Adaptive Learrning Scales. Retrieved from http://www.umich.edu/ $\sim$ pals/PALS\%202000_V13Word97.pdf

Otopah, F. O., \& Dadzie, P. (2013). Personal information management practices of students and its implications for library services. Aslib Proceedings: New Information Perspectives, 65(2), 143-160. https://doi.org/10.1108/00012531311313970

Pintrich, P., Smith, D., García, T., \& Mckeachie, W. (1991). A Manual for the use of the Motivated strategies of learning questionnaire (MSLQ). National Center for Research to Improve Postsecondary Teaching and Learning, Office of Educational Research and Improvement. Retrieved from http://files.eric.ed.gov/fulltext/ED338122.pdf

Prendes, M. P. (2010). Competencias TIC para la docencia en la Universidad Pública Española: Indicadores y propuestas para la definición de buenas prácticas: Programa de Estudio y Análisis. Retrieved from http://www.um.es/competenciastic

Prendes, M. P., Castañeda, L., Ovelar, R., \& Carrera, X. (2014). Componentes básicos para el análisis de los PLE de los futuros profesionales españoles: en los albores del Proyecto CAPPLE. EDUTEC, Revista Electrónica de Tecnología Educativa, 47, 1-15. https://doi.org/10.21556/ edutec.2014.47.139

Prendes, M. P., Castañeda, L., Solano, I., Roig, R., Aguiar, M. P., \& Serrano, J. L. (2016). Validation of a Questionnaire on Work and Learning Habits for Future Professionals: Exploring Personal Learning Environments. RELIEVE, 22(2), 1-46. https://doi.org/10.7203/relieve.22.2.7228

Prendes, M. P., \& Gutiérrez, I. (2013). Competencias tecnológicas del profesorado en las universidades españolas. Revista de Educación, 361, 196-222. https://doi.org/10.4438/1988-592X-RE -2011-361-140

Sedghi, S., Abdolahi, N., Azimi, A., Tahamtan, I., \& Abdollahi, L. (2015). A qualitative study on personal information management (PIM) in clinical and basic sciences faculty members of a medical university in Iran. Medical Journal of the Islamic Republic of Iran, 29(1), 777-783.

Sinn, D., Kim, S., \& Syn, S. Y. (2017). Personal digital archiving: influencing factors and challenges to practices. Library Hi Tech, 35(2), 222-239. https://doi.org/10.1108/LHT-09-2016-0103

Stewart, K. N., Basic, J., \& Erdelez, S. (2012). ODI and information literacy: Personal information management in a world of information overload. Proceedings of the ASIST Annual Meeting, 49(1), 1-4. https://doi.org/10.1002/meet.14504901260

Sureda, J., Comas, R., \& Urbina. (2007). Internet como fuente de documentación académica entre estudiantes universitarios: una aproximación a partir del alumnado de educación social de la Universitat de les Illes Balears. SIDOC. I Simposio Internacional de Documentación Educativa. Retrieved from https://redined.mecd.gob.es/xmlui/bitstream/handle/11162/5547/ 01220073000131.pdf? sequence $=1$

Syn, S. Y., Sinn, D., \& Kim, S. (2020). Impact of contexts, resource types and perceptions on information management within the personal domain among college students. Aslib Journal of Information Management, 6(72), 909-927. https://doi.org/10.1108/AJIM-05-2020-0163

Warraich, N. F., Ali, I., \& Yasmeen, S. (2018). Keeping found things found: Challenges and usefulness of personal information management among academicians. Information and Learning Sciences, 119(12), 712-720. https://doi.org/10.1108/ILS-07-2018-0064

Whittaker, S. (2011). Personal information management: From information con-sumption to curation. Annual Review of Information Science and Technology, 45, 1-62. https://doi.org/10.1002/ aris.2011.1440450108

Zhong, C. (2013). Research on personal information management. International Conference on Computational and Information Sciences Research (pp. 371-374). https://doi.org/10.1109/ ICCIS.2013.105 